OPEN ACCESS

Edited by:

Chien-Kuo Lee,

National Taiwan University, Taiwan

Reviewed by:

Alessandra Mancino,

San Raffaele Hospital (IRCCS), Italy

Cheng-Lung KU,

Chang Gung University, Taiwan

${ }^{*}$ Correspondence:

Trine H. Mogensen

trine.mogensen@biomed.au.dk

Specialty section:

This article was submitted to

Molecular Innate Immunity,

a section of the journal

Frontiers in Immunology

Received: 25 September 2018 Accepted: 10 December 2018

Published: 08 January 2019

Citation:

Mogensen TH (2019) IRF and STAT Transcription Factors - From Basic Biology to Roles in Infection, Protective Immunity, and Primary Immunodeficiencies.

Front. Immunol. 9:3047. doi: 10.3389/fimmu.2018.03047

\section{IRF and STAT Transcription Factors - From Basic Biology to Roles in Infection, Protective Immunity, and Primary Immunodeficiencies}

Trine H. Mogensen ${ }^{1,2,3 *}$

${ }^{1}$ Department of Infectious diseases, Aarhus University Hospital, Aarhus, Denmark, ${ }^{2}$ Department of Biomedicine, Aarhus University, Aarhus, Denmark, ${ }^{3}$ Department of Clinical Medicine, Aarhus University, Aarhus, Denmark

The induction and action of type I interferon (IFN) is of fundamental importance in human immune defenses toward microbial pathogens, particularly viruses. Basic discoveries within the molecular and cellular signaling pathways regulating type I IFN induction and downstream actions have shown the essential role of the IFN regulatory factor (IRF) and the signal transducer and activator of transcription (STAT) families, respectively. However, the exact biological and immunological functions of these factors have been most clearly revealed through the study of inborn errors of immunity and the resultant infectious phenotypes in humans. The spectrum of human inborn errors of immunity caused by mutations in IRFs and STATs has proven very diverse. These diseases encompass herpes simplex encephalitis (HSE) and severe influenza in IRF3- and IRF7/IRF9 deficiency, respectively. They also include Mendelian susceptibility to mycobacterial infection (MSMD) in STAT1 deficiency, through disseminated measles infection associated with STAT2 deficiency, and finally staphylococcal abscesses and chronic mucocutaneous candidiasis (CMC) classically described with Hyper-lgE syndrome (HIES) in the case of STAT3 deficiency. More recently, increasing focus has been on aspects of autoimmunity and autoinflammation playing an important part in many primary immunodeficiency diseases (PID)s, as exemplified by STAT1 gain-of-function causing CMC and autoimmune thyroiditis, as well as a recently described autoinflammatory syndrome with hypogammaglobulinemia and lymphoproliferation as a result of STAT3 gain-of-function. Here I review the infectious, inflammatory, and autoimmune disorders arising from mutations in IRF and STAT transcription factors in humans, highlightning the underlying molecular mechanisms and immunopathogenesis as well as the clinical/therapeutic perspectives of these new insights.

Keywords: IRF, STAT, interferon, antiviral, proinflammatory, primary immunodeficiency, genetics

\section{INTRODUCTION}

Several decades of research uncovering the basic biology, regulation; and functions of the machinery for induction and responses to type I interferon (IFN) have paved the way for an understanding of a number of very diverse human diseases arising when one or more molecules in these pathways are defective. In this manner, the study of humans with primary immunodeficiencies (PID)s provides important understanding 
of specific protective immunity in humans, an insight that cannot always be gained by studying experimental animal models. Moreover, the study of individuals with defects in these pathways may teach us valuable lessons about principles of basic cell biology and infection immunology. Finally, detailed knowledge on the fundamental immunopathogenesis allows for rapid and specific diagnosis and not least for targeted treatments for individuals with these rare inborn errors of immunity.

Several PIDs have been associated to the defective expression or function of molecules belonging to innate immune signaling receptors or pathways $(1,2)$. These discoveries have been accelerated by the introduction of whole exome sequencing (WES) techniques. Moreover, with the advent of such sequencing methologies, an increasing number of monogenic diseases caused by gain-of-function (GOF) mutations have emerged (3). This expands the spectrum of PIDs to also include conditions characterized by autoimmunity and autoinflammation.

\section{BASIC STRUCTURE, SIGNALING, AND BIOLOGY OF IRF AND STAT TRANSCRIPTION FACTORS}

\section{Recognition of Microbial Pathogens and Induction of IFNs by IRFs}

The innate immune system utilizes pattern recognition receptors (PRR)s to detect pathogen-associated molecular patterns (PAMP)s to mount protective immune responses, including production of cytokines and IFN (4). Production of type I IFN is induced following recognition of nucleic acids, mainly of foreign origin, but under certain pathological conditions deriving from the host. Different classes of PRRs are involved in induction of IFN, including membrane-associated Toll-like receptors (TLR)s, cytosolic RNA sensing retinoic acid inducible gene (RIG)-like receptors (RLR)s, and DNA sensors $(4,5)$. Each of these classes of PRRs activate IFN regulatory factor (IRF)s through unique adaptor molecules, known as TIR-domain-containing adapter inducing IFN $\beta$ (TRIF), mitochondrial antiviral signaling protein (MAVS) and stimulator of IFN genes (STING), respectively, to which IRF binds in order to become phosphorylated (6) (Figure 1).

\section{IRFs}

In mammals nine different IRF family members have been described. All IRF proteins have a conserved amino-terminal DNA binding domain (DBD) with a helix-loop-helix structure and a motif containing five tryptophan residues. IRF-association domains (IAD) 1 and 2 at the carboxyterminal region of IRFs mediate homodimeric and heterodimeric interactions with other IRF family members, transcription factors, and co-factors. Whereas IRF3 has restricted DNA binding properties, IRF7 exhibits broader DNA binding specificity, accounting for its capacity to induce several IFN $\alpha$ subtypes. The C-terminal signal response domain of IRF proteins contains several possible phosphorylation sites, of which phosphorylation at serine 386 for IRF3 or serine 477 and 479 at IRF7 are believed to represent the main activation sites (7). In addition, poly-ubiquitination of IRF7 at K63 by TRAF6 and the E2 enzyme complex Ubc13/Uev1A is required for IRF7 activation (8).

Transcriptional activation of the IFN $\beta$ promoter by IRF3/7 has been extensively studied $(9,10)$, and proceeds with phosphorylation of IRF3/7 by the kinase TKB1, leading to dimerization and translocation of IRF3/7 homo-or hetero-dimers to the nucleus together with other transcription factors, such as nuclear factor (NF)- $\mathrm{B}$ and activator protein (AP)-1 (11). Assembly of the enhanceosome on the IFN $\beta$ promoter leads to histone acetylation and displacement of the nucleosome, hereby allowing initiation of IFN $\beta$ gene transcription. Importantly, NF$\kappa \mathrm{B}$ can cooperate in the induction of IFNs, at least at the IFN $\beta$ promoter, whereas IRFs, on the other hand, do not take part in induction of proinflammatory cytokines, although they may indirectly stimulate their synthesis $(12,13)$. IRF3 appears to be constitutively expressed in many cell types, residing in the cytoplasm in an inactive form, which upon upstream activating signals induces transcription of a set of early transcribed type I and type III IFN genes (mostly IFN $\beta$, IFN $\alpha 4$, and IFN $\alpha 1$ ) $(13,14)$. IRF7 on the other hand, is a lymphoid transcription factor constitutively expressed only in B cells, monocytes and plasmacytoid dendritic cells (pDC)s (15). pDCs in particular express high levels of IRF7, while in most other cell types IRF7 is inducible from low levels of expression (16). Thus, early during infection IRF7 only has a minor contribution to the production of type I and type III IFNs. However, at later stages of infection, as more IRF7 is induced by type I IFNs, IRF7 induces the production of a delayed set of IFN $\alpha$ genes, including IFN $\alpha 2, \alpha 5$, $\alpha 6$, and $\alpha 8$, as well as IFN $\beta 2$ and $\operatorname{IFN} \beta 3(14,17,18)$ (Figure 1). This generates a positive feedback loop, as type I and III IFNs induce more IRF7, thus leading to production of even more type I and type III IFNs, and this amplification loop is believed to play an important role in the generation of an immediate and potent response to virus infection (16).

\section{The Interferons}

Type I IFNs were initially discovered as soluble factors mediating viral interference (19), and subsequent work allowed the cloning, sequencing, and functional characterization of this group of cytokines (11, 20-24). Whereas type I IFNs (IFN $\alpha$ and IFN $\beta$ ) are predominantly expressed by innate immune cells, the functionally similar type III IFNs, (IFN $\lambda 1-4$ ), discovered in 2003, are more restricted and primarily act on epithelial surfaces $(17,25)$. Finally, type II IFN (IFN $\gamma$ ), discovered in 1965, is being synthesized by Natural killer (NK) cells and T cells and exerts antiviral functions mainly by activating macrophages (25). Type I IFNs exert a broad range of antiviral activities, including induction of the classically described molecules dsRNA-activated protein kinase $\mathrm{R}(\mathrm{PKR})$ which inhibits the cellular translational machinery, $2^{\prime}-5^{\prime}$-oligoadenylate synthetase (OAS)/RNAseL with the capacity to degrade foreign RNA, and $\mathrm{Mx}$ proteins that mainly restrict influenza virus through an itranuclear GTPase activity (11). Moreover, a wide range of IFN-inducible genes (ISG)s with diverse effects on antiviral defenses and cell proliferation and differentiation are induced and mediate the pleiotropic effects of type I (and III) IFNs (11). 


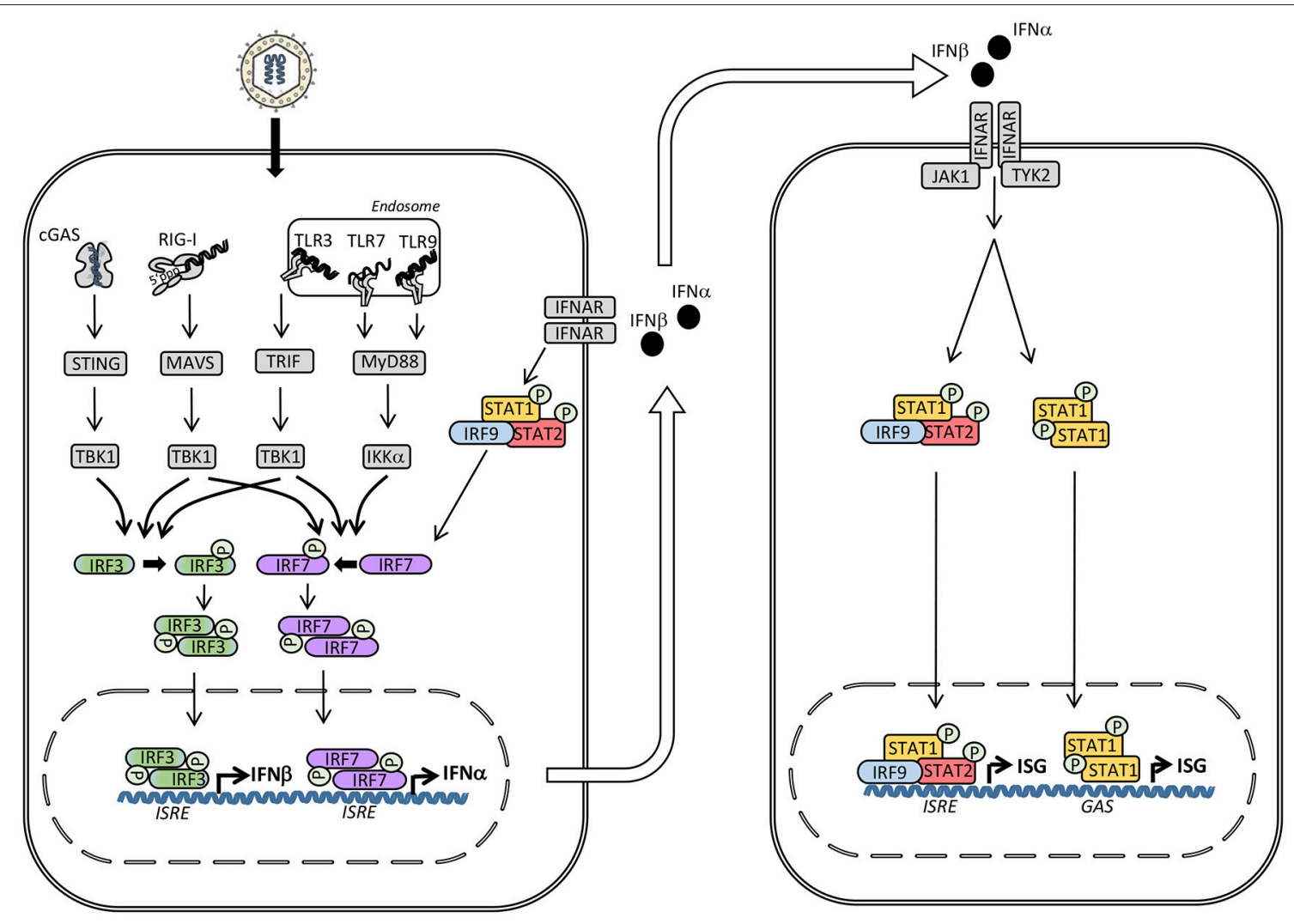

FIGURE 1 | Induction of type I interferon (IFN) and signaling by the type I IFN receptor. The presence of microbial or self-nucleic acid in the cytosol or within the endosomal compartment activates pattern recognition receptors (PRR)s. RNA activates retinoic acid-inducible receptor (RIG)-I in the cytosol and Toll-like receptor (TLR)3 and TLR7 in the endosomal compartment, whereas DNA is sensed by cyclic GMP-AMP synthase (cGAS) in the cytosol and by TLR9 within endosomes. These events trigger signaling pathways through the adaptor molecules stimulator of IFN genes (STING), mitochondrial antiviral signaling protein (MAVS),

TIR-domain-containing adapter-inducing interferon- $\beta$ (TRIF), and Myeloid differentiation primary response (MyD)88 leading to phosphorylation and activation of the TANK binding kinase (TBK)1, which in turn phosphorylates the transcription factors IFN regulatory factor (IRF) 3 and IRF7. Whereas IRF3 is constitutively present, IRF7 is expressed at low levels but may be secondarily induced by type I IFN. Phosphorylation of IRF3 and IRF7 leads to homodimerization, nuclear translocation, and expression of type I IFNs (IFN $\alpha$ and IFN $\beta$ ) acting on neighboring cells with type I IFN receptors. Type I IFN binds to IFN $\alpha / \beta$ receptor (IFNAR) 2 leading to recruitment of IFNAR1 and formation of a complex that activates the receptor-associated Janus-associated kinase (JAK)1 and tyrosine kinase (TYK)2 and subsequent tyrosine phosphorylation of STAT1 and STAT2. These activated transcription factors together with IRF9 form the heterotrimeric transcription factor IFN-stimulated gene factor (ISGF) 3 complex which binds to IFN-stimulated regulatory elements (ISRE) in DNA. In addition, STAT1 homodimers form the IFN- $\gamma$-activated factor (GAF) complex which binds to IFNg-activated sequences (GAS). Altogether, these transcription factors induce a broad spectrum of IFN-stimulated genes (ISG)s that mediate the complex "antiviral state" of IFNs.

\section{JAK-STAT Molecules}

The evolutionarily conserved Janus kinase-signal transducers and activators of transcription (JAK-STAT) signaling pathway mediates responses to a number of important cytokines and growth factors (26) (Figures 1, 2). The specific responses to JAKSTAT signaling are therefore highly dependent on the cellular context and include proliferation, differentiation, migration, apoptosis, and cell survival (27). As a consequence, JAKSTAT pathways are involved in various physiological processes, including innate and adaptive immune responses, hematopoiesis, growth, and development (28). The identification of the JAKSTAT pathway was the result of seminal work performed by several scientists, including Darnell, Stark, and Kerr in the search for molecules mediating IFN-induced signaling (29). Four members of the JAK family (JAK1, 2, 3, and tyrosine kinase (TYK) 2 and seven members of the STAT family (STAT1, 2, 3, 4,
5A, 5B, and 6) have been identified (28). JAKs belong to a class of tyrosine kinases characterized by containing both a catalytic domain and a kinase-like domain with autoregulatory function (29). By functional screening, these kinases were subsequently functionally linked to the transcription factors STATs (26). The overall structure of STAT proteins consists of coiled coil (CC) domain, a DNA binding domain (DBD), and an $\mathrm{SH} 2$ domain (29).

\section{JAK-STAT Signaling Downstream of the IFN Receptor}

Type I IFNs act via the IFN $\alpha / \beta$ receptor (IFNAR) 1 and IFNAR2, type III IFN signals through IFNLR1 and IL10R2, whereas IFN $\gamma$ acts via IFNGR1 and IFNGR2 (11) (Figure 1). The binding of type I IFN induces formation of a receptor complex between 


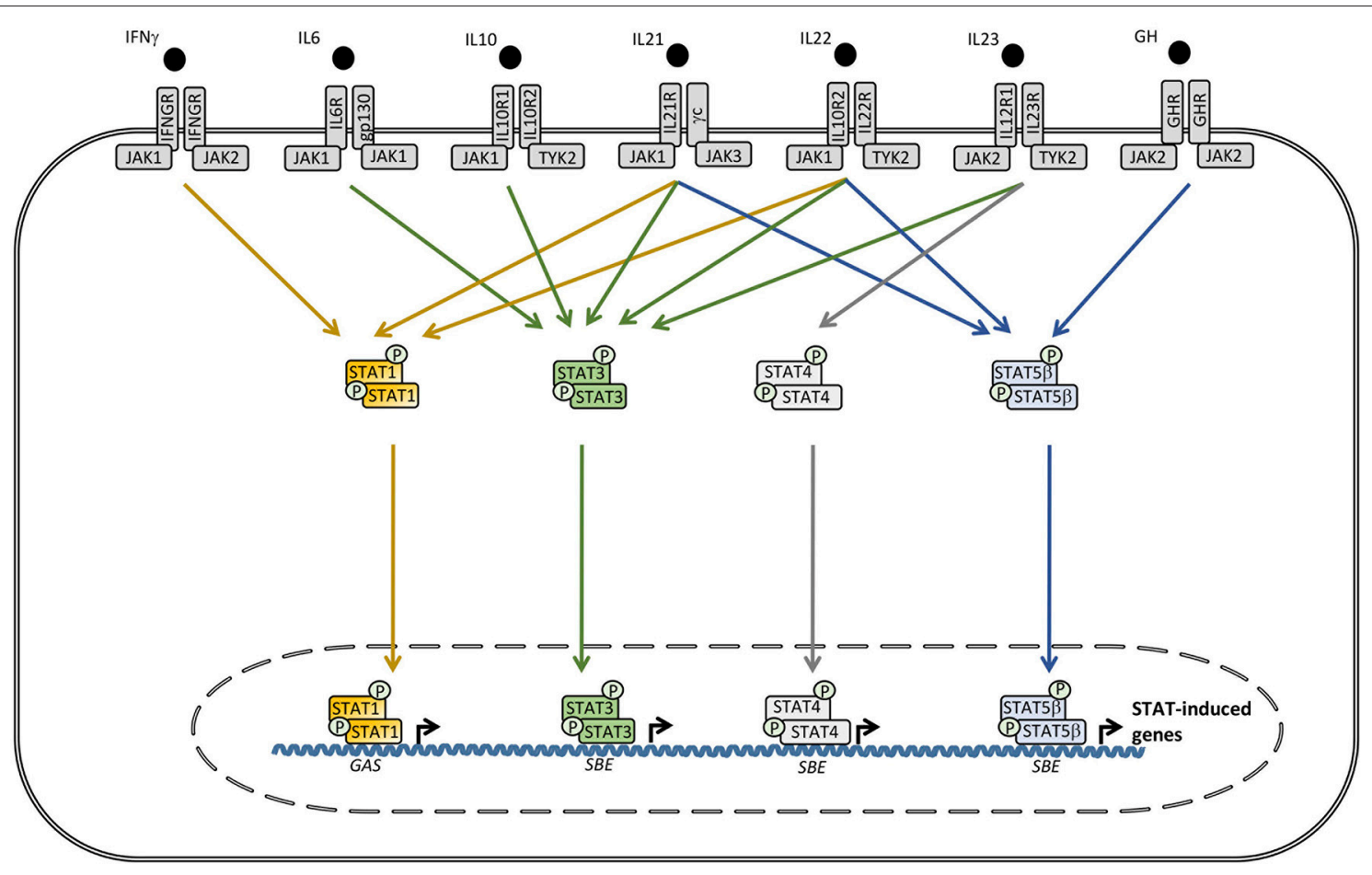

FIGURE 2 | A wide range of cytokines, including interleukin (IL)6, IL10, IL21, IL22, IL23, IFN $\gamma$, and growth factors activate receptors utilizing different combinations of the tyrosine kinases janus activated kinase (JAK)1, JAK2, and tyrosine kinase (TYK)2 which trigger signaling pathways involving signal transducer and activator of transcription (STAT)1, STAT3, STAT4, and STAT5A/B. Phosphorylated STAT3 can homo- or heterodimerize with other STAT3 molecules or STAT1 or STAT5, respectively. STAT complexes modulate transcription of various genes, including increased IL6, IL10, IL17A/17F, IL22, transforming growth factor (TGF) $\beta$, and monocytic chemotactic protein (MCP)1 production, as well as decreased tumor necrosis factor (TNF) $\alpha$, IL12, and IFN $\gamma$ synthesis. SBE, STAT binding element. GAS, $\gamma$-IFN-activated sequence.

IFNAR1 and IFNAR2, leading to activation of the receptorassociated JAK1 and TYK2 kinases $(11,22,25)$. This is followed by recruitment and tyrosine phosphorylation of STAT1 and STAT2, which together with the transcription factor IRF9 form the heterotrimeric IFN-stimulated gene factor (ISGF) 3 complex that binds to IFN-stimulated regulatory elements (ISRE) $(26,28$, 29). In addition, phosphorylated STAT1 homodimers, termed IFN- $\gamma$-activated factor (GAF), are activated and in a similar manner induce transcription from $\gamma$-IFN activation sequence (GAS) (30) (Figure 1). Signaling from the type III IFN receptor is similar. In the case of type II IFN, binding of IFN $\gamma$ induces homodimerization of IFNGR1 subunits and recruitment of IFNGR2 subunits, and this association induces phosphorylation and activation of JAK1 and JAK2 kinases, ultimately leading to phosphorylation of STAT1 to form the GAF complex as well as weak activation of the ISGF3 complex (11).

\section{STAT3 Signaling Downstream of Multiple Cytokine and Growth Factor Receptors}

The STAT3 molecule was discovered by Akira et al. by purification and cloning and was found to bind to the interleukin (IL)6 responsive element of the acute phase response promoter (31). Simultaneously STAT3 was described by another group as a DNA binding protein downstream of the epidermal growth factor receptor (32). Pathways involving
STAT3 activation are triggered by a number of cytokines and growth factors (27) (Figure 2). Receptor binding of the ligand leads to recruitment of intracellular JAK2 and TYK2, resulting in specific phosphorylation on STAT3 at tyrosine 705, allowing dimerization, nuclear translocation, and transcriptional activation of target genes (27). Phosphorylated STAT3 primarily homodimerize but also has the capacity to heterodimerize with STAT1 and STAT5, thereby inducing differentiated transcriptional programs (Figure 2). The 770 amino acid STAT3 molecule may be further post-translationally modified by phosphorylation, methylation, and acetylation, contributing to functional regulation $(27,28)$. The set of genes induced by actvated STAT3 is extraordinarily high and diverse, including IL10, IL17A/F, IL22, IL26, transforming growth factor (TGF) $\beta$, IL6, and monocytic chemotactic protein (MCP) 1. In contrast, pro-inflammatory mediators, such as tumor necrosis factor (TNF) $\alpha, I F N \gamma$, and IL12, are downregulated through STAT3-mediated signaling pathways (27) (Figure 2).

\section{DISEASES ASSOCIATED WITH DEFECTIVE IRF SIGNALING}

In the second part of this review, presently known PIDs associated with defects in IRF and STAT transcription factors 
TABLE 1 | Mutations in IRFs and STATs, functional impact, and associated PID/infectious phenotype.

\begin{tabular}{|c|c|c|c|}
\hline Gene & Inheritance & Allele & $\begin{array}{l}\text { PID and infectious } \\
\text { phenotype }\end{array}$ \\
\hline IRF3 & $\mathrm{AD} / \mathrm{IP}$ & LOF & $\begin{array}{l}\text { Herpes simplex } \\
\text { encephalitis (HSE) }\end{array}$ \\
\hline IRF7 & $\mathrm{AR}$ & LOF & Severe influenza \\
\hline IRF8 & $\mathrm{AR}$ & LOF & $\begin{array}{l}\text { Mendelian susceptibility } \\
\text { to mycobacterial } \\
\text { infection (MSMD) }\end{array}$ \\
\hline IRF9 & $\mathrm{AR}$ & LOF & Severe influenza \\
\hline STAT1 & $\mathrm{AD} / \mathrm{AR}$ & LOF & MSMD, HSE, fungi \\
\hline STAT1 & $A D$ & GOF & $\begin{array}{l}\text { Chronic } \\
\text { mucocutaneous } \\
\text { candidiasis (CMC), } \\
\text { progressive multifocal } \\
\text { leukoencephalopathy } \\
\text { (PML)/JC virus }\end{array}$ \\
\hline STAT3 & $A D$ & LOF & $\begin{array}{l}\text { Hyper-lgE syndrome } \\
\text { (HIES), Staphylococcus } \\
\text { aureus, Candida } \\
\text { albicans, aspergillus, } \\
\text { EBV }\end{array}$ \\
\hline STAT3 & $A D$ & GOF & $\begin{array}{l}\text { Autoinflammation, } \\
\text { hypogammaglobulinemia }\end{array}$ \\
\hline STAT5B & $A D$ & LOF & $\begin{array}{l}\text { Growth hormone } \\
\text { insensitivity syndrome } \\
\text { (GHIS) with a broad } \\
\text { infectious phenotype }\end{array}$ \\
\hline
\end{tabular}

IRF, interferon (IFN) regulatory factor; STAT, signal transducer and activator of transcription; $A D$, autosomal dominant, $A R$, autosomal recessive; $L O F$, loss-of-function; GOF, gain-offunction.

are described, including the clinical presentation, infectious phenotype and the genetic and immunological basis of disease. An overview of individual genetic defects and associated PIDs is given in Table 1, and the signaling pathways and transcription factors affected by either defective or excessive function of IRFs and STATs are illustrated in Figures 3, 4.

\section{IRF3 Deficiency and Herpes Simplex Encephalitis}

A number of seminal discoveries by Casanova and colleagues described an essential non-redundant role of TLR3 signaling, including TLR3, UNC93B, TRIF, TRAF3, and TBK1, and the generation of type I IFN responses in the central nervous system (CNS) in protection against herpes simplex encephalitis (HSE) (33-37). Based on this work, our group additionally described a patient with defective IRF3 signaling and HSE (38) (Figure 3). The patient, who was a 16-year-old adolescent, suffered from a severe episode of HSE with convulsions and neurological deficits and was found to have impaired type I IFN production in response to HSV-1 and number of viral PAMPs. More specifically, the R285Q IRF3 mutation resulted in change from the positively charged arginine to the neutral glutamine, causing functionally defective phosphorylation, dimerization, and transcriptional activation of IRF3 (38). Since no dominant negative effect of the IRF3 variant could be demonstrated, it was concluded that the mechanism was haploinsufficiency and that the inheritance was autosomal dominant (AD) with incomplete penetrance. The causal relationship between heterozygous IRF3 deficiency and HSE was supported by the reconstitution of patient fibroblasts with wild-type (wt) IRF3, resulting in normal production of type I and III IFN in response to HSV and the TLR3 ligand Poly(IC). The infectious history of the patient, like the vast majority of previously described HSE patients with defects in TLR3 signaling pathways, was notable for no previously reported increased susceptibility to other infections, suggesting specificity in the susceptibility to HSV-1 infection and development of CNS infection (38). This very narrow infectious phenotype caused by a defect of a transcription factor, which represents a point of convergence downstream of several IFN-inducing PRRs appears surprising. However, this observation may be, at least partly, explained by the more pronounced impact of the specific R285Q IRF3 mutation on the functional interaction with the TLR3 pathway adaptor molecule TRIF, than between IRF3 and the adaptor molecules MAVS and STING of the RIG-I and DNA sensor signaling pathways, respectively, $(6,38)$. Importantly, a second patient with a different IRF3 variant was subsequently described in a cohort of adult patients with HSE, providing further support for IRF3 as a genetic etiology for HSE (39). Also of relevance is a case report describing the presence of a TLR3 variant in a patient with recurrent HSV-2 meningitis (Mollaret's meningitis), thus adding another piece of data to the notion of an important role of the TLR3 signaling pathway for mounting protective IFN responses during HSV-1 and HSV2 neuroinfections (40). Importantly, this is paralleled by an earlier study showing increased susceptibility to HSV-1 infection in the brain in IRF3-deficient mice (41).

\section{IRF7 and IRF9 Deficiency and Severe Influenza}

Despite a number of single nucleotide polymorphisms (SNP)s identified by genome wide association studies (GWAS) in patients with severe disseminated influenza infection, as well as evidence from mouse studies of an essential role of IFN in antiviral defenses against Influenza virus, the first monogenic defect associated with severe influenza was only described in 2015 $(42,43)$. The authors described homozygous IRF7 deficiency in a 2.5-year-old girl with severe influenza and acute respiratory distress syndrome (Figure 3). Functional studies demonstrated abolished type I IFN production in pDCs in response to Influenza A virus (IAV) and consequently elevated IAV replication in fibroblasts. The results were were further supported by including airway epithelial cells derived from induced pluripotent stem cells from the patient revealing impaired IAV replication and reduced IFN production (42).

Again the common theme is a relatively narrow infectious phenotype of the patient in contrast to Irf7 knock-out mice which exhibit elevated susceptibility to a number of RNA- and DNA viruses $(44,45)$. Finally, there are some remaining pieces to the puzzle, since the infectious phenotype of patients with mutations in IRF3 and STAT1 that impair induction and responsiveness to type I IFN, respectively, have not revealed a similar increased risk 


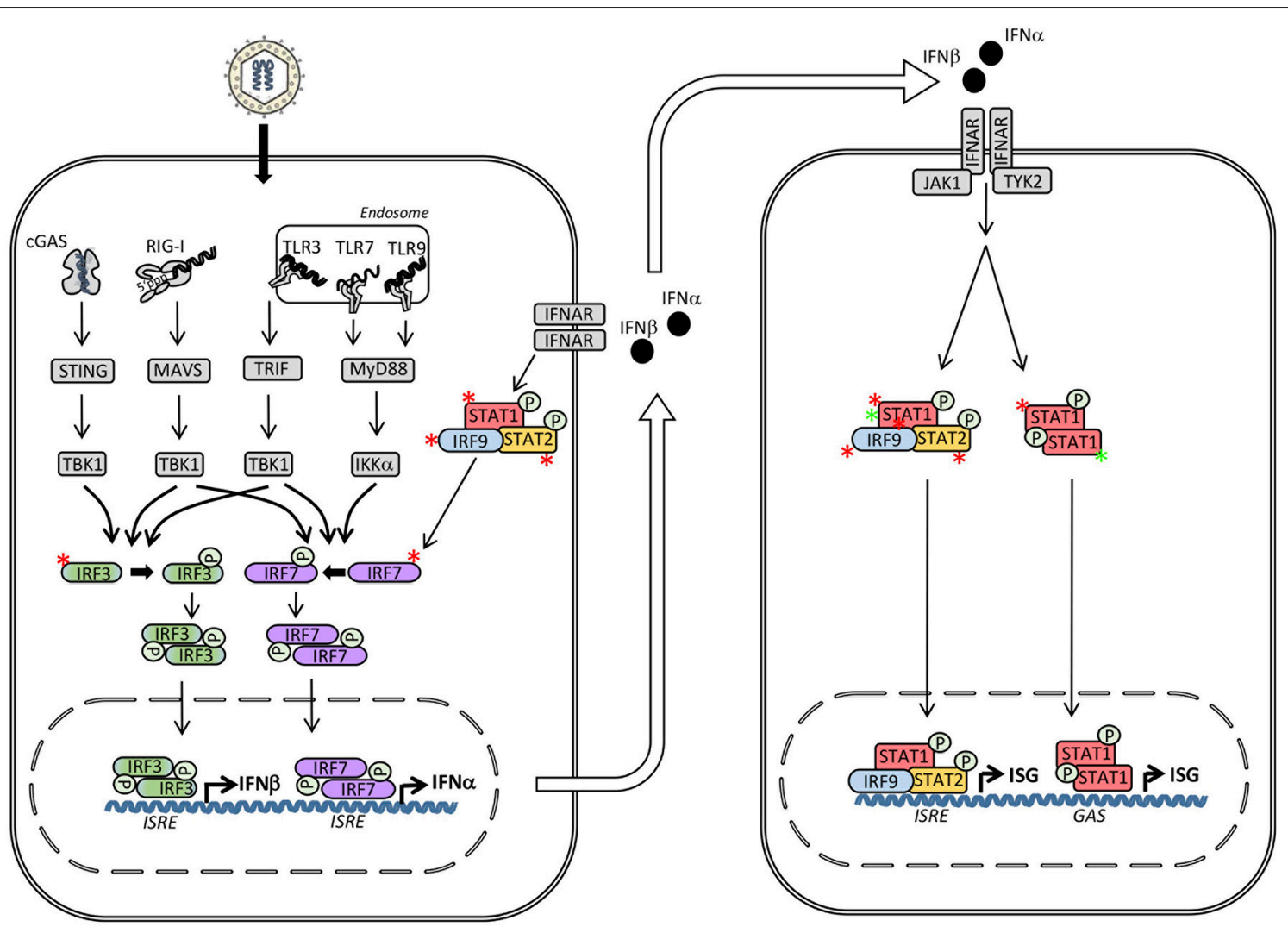

FIGURE 3 | Inborn errors of immunity in interferon (IFN) regulatory factors (IRF)s and signal transducers and activators of transcription (STAT)s may lead to either loss-of-function (LOF) (red asterisk) or gain-of-function (GOF) (green asterisk) of the molecule and result in different primary immunodeficiencies (PID)s and infectious phenotypes. Within the IFN inducing signaling pathways defects in IRF3, IRF7, IRF9, and IRF8 result in herpes simplex encephalitis (HSE), severe influenza, and Mendelian susceptibility to mycobacterial disease (MSMD), respectively. Defects downstream of the type I IFN receptor in STAT1, STAT2 or IRF9 cause MSMD, susceptibility to measles, and severe influenza, respectively. In contrast, STAT1 GOF causes chronic mucocutaneous candidiasis (CMC). ISRE, IFN stimulated response element; GAS, $\gamma$-IFN-activated sequence.

of severe influenza infection $(38,46)$. This intriguing observation may suggest a particularly important role of the IRF3-IRF7 amplification loop for rapid production of large amounts of IFN $\beta$ as well as multiple IFN $\alpha$ subtypes in antiviral defense against IAV in lung tissue and/or alveolar macrophages (43).

Recently, life-threatening influenza was also reported in a child with autosomal recessive (AR) homozygous IRF9 deficiency (47) (Figure 3). Since IRF9 acts downstream of type IFN as part of the ISGF3 complex, IRF9 deficiency represents a defect in the response to IFN rather than in the induction of IFN responses. Prior to admission with severe influenza at the age of 5 years, the patient had an infectious history with several hospital admissions with RSV bronchiolitis, severe disease with biliary perforation presumably secondary to vaccination with the measles-mumps-rubella (MMR) vaccine, and frequent fevers. Based on serological evidence of infections with HSV, cytomegalovirus (CMV), rhinoviruses, and enteroviruses without particularly severe clinical infections, the report suggested a relatively narrow phenotype of IRF9 deficiency (47). The authors demonstrated normal responses to STAT1 homodimers and STAT1/2 heterodimers from a GAS promoter in contrast to impaired responses from an ISRE promoter downstream of the heterotrimer STAT1/STAT2/IRF9 (47) (Figure 3). The causal relationship between homozygous IRF9 deficiency and increased susceptibility to influenza was convincingly demonstrated by the rescue of IFN responses and control of viral replication after expression of wt IRF9 in patient cells (47). In addition to IRF7 and IRF9 deficiency predisposing to severe influenza, a RIG-I variant has also been described in an adult patient with severe influenza (48). Altogether, these reports demonstrate an important role of type I (and possibly type III) IFN in antiviral immunity to influenza virus in humans.

\section{DISEASES ASSOCIATED WITH DEFECTIVE STAT SIGNALING}

\section{STAT1- and IRF8 Deficiency and Mendelian Susceptibility to Mycobacterial Disease}

AD STAT1 deficiency was among the first genetic etiologies of mycobacterial disease to be described (49) (Figure 3). This condition, which was termed Mendelian susceptibility to mycobacterial disease (MSMD), primarily leads to severe infection with atypical mycobacteria and the weakly virulent 


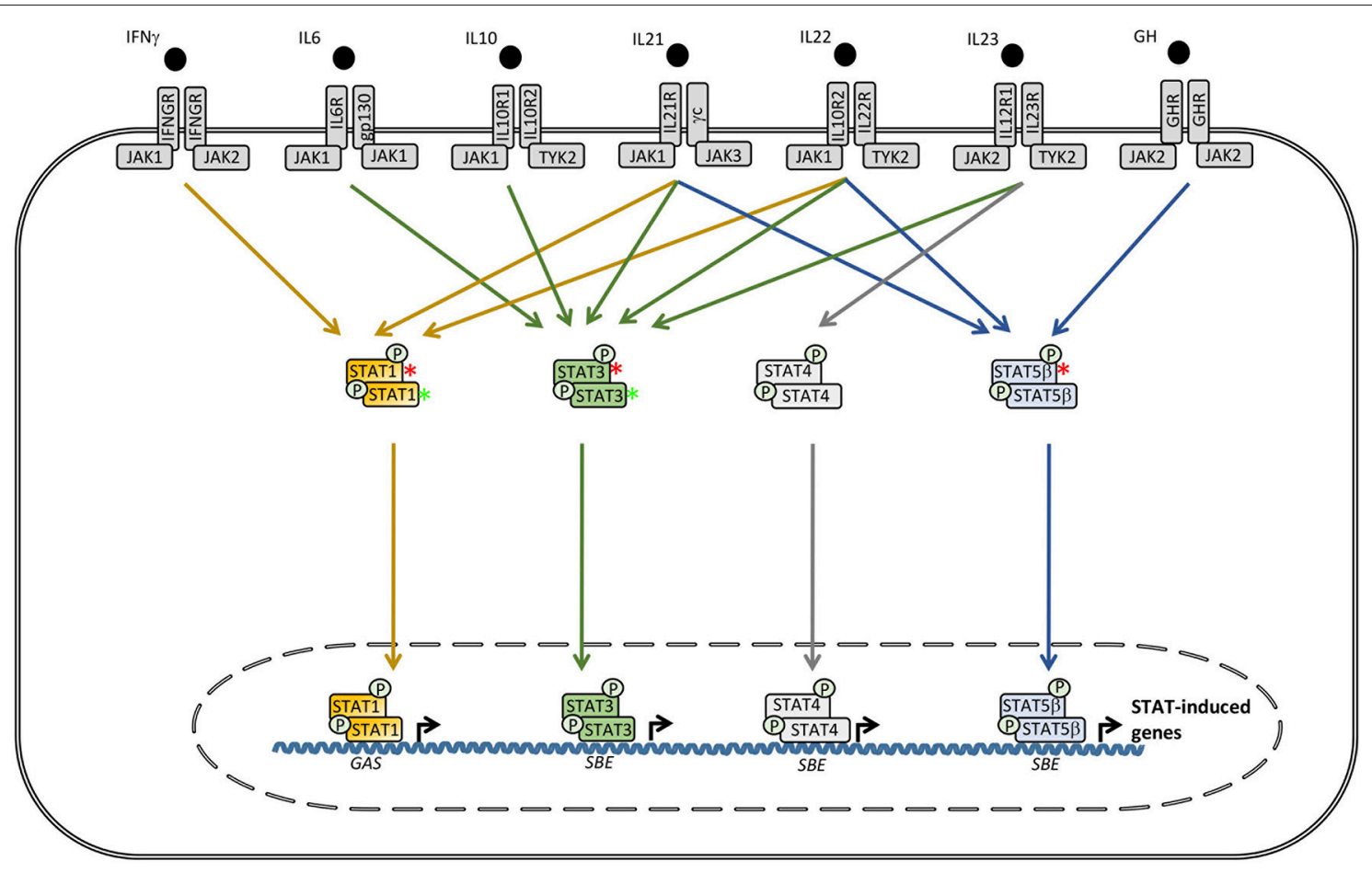

FIGURE 4 | Defects downstream of various receptors utilizing signal transcducer and activator of transcription (STAT)1, STAT3, or STAT5B cause Mendelian susceptibility to mycobacterial disease (MSMD), hyper-lgE syndrome (HIES) and growth hormone insensitivity syndrome (GHIS), respectively. In contrast, STAT1 GOF causes chronic mucocutaneous candidiasis (CMC), whereas, STAT3 GOF leads to an autoinflammatory condition with hypogammaglobulinemia, lymphoproliferation, and a broad infectious phenotype. SBE, STAT bindinf element; GAS, $\gamma$-IFN-activated sequence.

Bacille-Calmette-Guerin (BCG) vaccine strain. However, severe viral infections, particularly HSE, and increased susceptibility to certain intracellular bacteria, including Listeria monocytogenes and salmonella species, as well as fungi have also been described (50-52). The fundamental and non-redundant role of the IL12-IFN $\gamma$ circuit in the intercellular communication between macrophages/dendritic myeloid cells and T/NK cells in immunity to mycobacteria has been reinforced by the reports of several defective molecules within these pathways giving rise to MSMD with a very similar phenotype. Thus, MSMD can also originate from defects in IL12 p40, IL12RB1, IFNGR1, IFNGR2, NEMO, ISG15, TYK2, CYBB, IRF8, and most recently in SPPL2a (50-63). In addition, mycobacterial infection is a prominent feature of the MonoMAC syndrome caused by GATA2 mutations $(64,65)$. While various heterozygous STAT1 mutations were described to be associated with impaired IFN $\gamma$ responses (49, 66), an intriguing aspect of AD STAT1 heterozygous dominant MSMD is the apparent partial preservation of IFN $\alpha / \operatorname{IFN} \beta$ responses and lack of broad susceptibility to viruses, as might have been expected, given the central position of STAT1 downstream of the type I IFN receptor $(29,67,68)$ (Figure 3). However, when the first patient with AR STAT1 defect, with complete loss of STAT1 function, was identified, it turned out that this phenotype indeed does show increased susceptibility to a broad range of viral infections in addition to $\operatorname{MSMD}(2,58)$. In addition, patient cells are unresponsive to both IFN $\gamma$ as well as to IFN $\alpha$ and IFN $\beta$, and even also to IFN $\lambda$ and IL27 (69). Finally, hypomorphic STAT1 alleles have been described to underlie AR STAT1 deficiency and display a milder, partial phenotype $(46,70-72)$.

Altogether, MSMD is a clear example of a PID with a relatively narrow infectious phenotype that may originate from a number of molecules belonging to the same functionally connected immunological pathway.

\section{STAT2 Deficiency and Fulminating Vaccine Strain Measles Virus Infection}

Whereas STAT1 deficiency, together with other genetic abnormalities in the macrophage - $\mathrm{T}$ cell circuit governing IL12-IFN $\gamma$ immunity, gives rise to MSMD, STAT2 deficiency was reported in 2013 to cause a narrow infectious phenotype with a fulminating disease course in a 5-year old child following MMR vaccination (73) (Figure 3). Moreover, an infant brother died from a febrile illness following a presumed viral infection of unknown etiology. Detailed studies revealed a homozygous mutation in intron 4 of STAT2 preventing correct RNA splicing in patient cells. In addition, the authors demonstrated absence of STAT2 protein expression, significantly impaired type I IFN signaling, as well as abnormal permissiveness to viral replication in patient cells in vitro (73). Intriguingly however, patients with STAT2 deficiency have not been described to suffer from neither mycobacterial infection, nor a broad spectrum of viral infections, which might have been anticipated based on profoundly defective IFN responses found in vitro. This may 
suggest partial redundancy between STAT1 and STAT2 with a dominating role of STAT1 in terms of immunity to mycobacteria, i.e., in individuals with STAT1 deficiency STAT2 can partially compensate with regards to mycobacterial infection, whereas STAT1 cannot compensate for the lack of STAT2 when it comes to measles virus infection.

\section{STAT3 Defect and Hyper-IgE Syndrome With Prominent Infectious- and Somatic Phenotypes}

Already in the initial description Hyper-IgE syndrome (HIES), originally termed Job's syndrome, "cold" abscesses caused by Staphylococcus aureus was described as a prominent feature (74). Other characteristics include eczematoid rashes presenting already during the neonatal period, recurrent sinopulmonary infections, skin abscesses, chronic mucocutaneous candidiasis (CMC), and eosinophilia, in combination with significantly elevated serum $\operatorname{IgE}>2,000 \mathrm{IU} / \mathrm{mL}$, and frequently even higher $(75,76)$. Fungal infections with Pneumocystic jirovecii, histoplasma, coccidioides and cryptococcus have been described to cause mucocutaneous- and gastrointestinal infections as well as meningitis. Moreover, AD HIES patients have been reported to exhibit increased susceptibility to VZV reactivation and Epstein-Barr virus (EBV) viremia $(77,78)$. The complexity of $\mathrm{AD}$ HIES pathogenesis is evidenced by the extensive list of non-immunological manifestations reported $(76,78)$. Abnormal craniofacial features include characteristic facies, craniosynostosis, high-arched palate, and sometimes retained childhood dentition $(79,80)$. Within the musculoskeletal system hyperextensibility, scoliosis, osteoporosis, and minimal trauma fractures are observed (76). Increasing awareness has also been on vascular abnormalities, including coronary artery aneurisms and hypertension (81). Similarly to many other PIDs, AD-HIES patients are at an increased risk of developing malignancies, particularly non-Hodgkin lymphoma (82).

The identification of STAT3 as the genetic origin of HIES in 2007 paved the way for a much more detailed understanding of the pathogenesis underlying the immunological abnormalities and infectious disease spectrum as well as the somatic features observed in this disease $(83,84)$ (Figure 4). The first study, revealed increased innate immune responses and impaired IL6 signaling, and further identified both inherited familial and sporadic mutations within the STAT3 locus in patients with HIES (83). These STAT3 mutations were either missense mutations or in-frame deletions and appeared to be localized primarily within the SH2-domain or the DBD of the molecule and act by a dominatint negative mechanism $(83,84)$. However, when mutations were present within the DBD of STAT3, expression, phosphorylation, and nuclear translocation of STAT3 were found to be normal compared to the situation in healthy controls (84). In contrast, in patients harboring STAT3 mutations affecting the SH2 domain or the trans-activating domain, cellular STAT3 phosphorylation at tyrosine 705 was reduced (85). The specific mechanism, by which STAT3 mutations abolish the function of the molecule, therefore remains to be fully clarified.
The central role played by STAT3 in signaling downstream of IL6 is believed to explain a substantial part of the immunodeficiency observed in AD HIES patients (83). This notion is supported by a report describing severe staphylococcal infection in a child with anti-IL6-antibodies, providing further evidence that IL6 is critical in response to human infection with staphylococci (86). Moreover, STAT3 has been shown to negatively regulate type I IFN responses and inflammatory TLR signaling (87). A hallmark of AD HIES is the presence of impaired Th17 responses, and accordingly STAT3 mutations have been demonstrated to result in a failure of Th17 T cell differentiation $(88,89)$. IL17 signaling also plays a role in neutrophil proliferation and chemotaxis, possibly explaining abnormal neutrophil responses and - recruitment to lung and skin causing recurrent staphylococcal infection in these organs and tissues in HIES $(90,91)$. Concerning the origin of the highly elevated IgE levels characteristic of the disorder, this feature has been suggested to reflect a role for STAT3 downstream of IL21 receptor signaling, based on the observation of elevated IgE levels in mice deficient in $\operatorname{IL} 21 \mathrm{R}(83,92)$ (Figure 4). Notably, HIES also exists in an AR form that may be caused by defects in either TYK2, dedicator of cytokinesis (DOCK)8, or phosphoglucomutase (PGN)3, although these present with a somewhat different phenotype, including a more pronounced tendency toward cutaneous viral infections and without the somatic phenotype characteristic of AD HIES resulting from STAT3 mutations (78, 93-95). However, TYK2 deficiency as a genetic cause of HIES remains controversial, since TYK2 deficient patients presenting with mycobacterial and viral infections in the absence of HIES have been reported (56).

\section{STAT5B Deficiency in Patients With Short Stature and Immunodeficiency}

STAT5B plays a key role downstream of the IL2 receptor and the growth hormone receptor (GHR), explaining why STAT5B defect causes Growth hormone insensitivity syndrome (GHIS) with a complex infectious and somatic phenotype (Figure 4). This medical condition was first described by Kofoed et al. in 2003 and constitutes a syndrome with short stature, facial dysmorphism, autoimmune manifestations, and severe infections $(9,10)$. The spectrum of autoimmune manifestations include autoimmune thyroiditis, idiopathic thrombocytopenic purpura, lymphocytic interstitial pneumonitis, and eczema (9, 10, 96). Although STAT5A and STAT5B molecules are very similar and share a high degree of identity, they differ in both DNA bindingand transactivation domains, providing and explanation for the non-redundant roles of STAT5B in human growth and immunity. The immunological phenotype includes a reduced number of $\mathrm{CD}^{+}{ }^{+} \mathrm{CD} 25$ high Foxp3 ${ }^{+}$cells in STAT5B patients, which is thought to contribute to the immune dysregulation of the disease (67). Indeed, studies in Stat5a/Stat5b doubledeficient mice have demonstrated reduced numbers of Treg cells, functionally connected to the development of autoimmunity and lymphocytic infiltrations (97). Moreover, based on the immune phenotype in mice, an increased rate of $\mathrm{T}$ cell apoptosis has been suggested to contribute to $\mathrm{T}$ cell lymphopenia and the broad 
susceptibility to infections observed in STAT5B deficient patients (67). Finally the insensitivity to GH originates from the role of STAT5B in inducing expression of insulin growth factor (IGF)-1 following GHR activation and STAT5B phosphorylation by JAK2 (67) (Figure 4).

\section{DISEASES ASSOCIATED WITH EXCESSIVE STAT SIGNALING \\ STAT1 Gain-of-Function in Th17 Deficiency and Chronic Mucocutaneous Candidiasis}

A common theme in several PIDs is that different mutations in a given molecule may have rather different functional consequences and impact and hence may result in entirely different clinical pictures (3). A good example of this is the major difference between STAT1 deficiency (described above) as opposed to the disease caused by STAT1 gain-of-function (GOF) (Figures 3, 4). Two groups of investigators independently established heterozygous STAT1 GOF as a cause of Th17 deficiency and AD CMC. Van de Veerdonk et al. analyzed 5 different families constituting 14 cases of $\mathrm{AD} \mathrm{CMC}$, leading to the finding of defective production of IFN $\beta$, IL17, and IL22 in response to candida, and the identification of heterozygous mutations within conserved residues in exon 10 encoding the CC domain of STAT1 (98). Simultaneously, Liu et al. identified heterozygous variations in the STAT1 gene within the CC domain by WES (16). Functional analyses of the mutant alleles revealed GOF mutations by a mechanism involving impaired nuclear dephosphorylation of Stat1, and indeed, nuclear dephosporylation rather than cytosolic hyperphosphorylation may be the dominant molecular mechanism underlying the immunological abnormalities in STAT1 GOF (99). Altogether, several different amino acid changes have been reported to cause either STAT1 LOF or GOF, most prominently in the CC domain and the DB domain of the molecule, although the precise functional impact of individual mutations may be difficult to estimate by bioinformatics alone, but requires mutagenesis studies (89, 98-104). Moreover, autoimmunity is a common feature of this patient population. Thyroid disease, enteropathy, alopecia, autoimmune cytopenias, type I diabetes and systemic lupus erythematosus-like disease have been reported (105). More recently, progressive multifocal leukoencephalopathy (PML) caused by reactivation of JC virus was described in a small number of patients with STAT1 GOF, indicating a profound T cell deficiency in this condition (98).

Several hypotheses have been presented to explain the molecular mechanism, whereby STAT1 GOF impairs the development of Th17 cells and IL17 responses (89). One of these states that STAT1 counteracts the gene expression induced by STAT3 downstream of Th17 cell differentiating- and generating signals, such as IL6, IL21, and IL23 signaling (106) (Figure 4). Another idea is that exaggerated IFN $\alpha / \beta$ - and IL27 responses inhibit the development of the Th17 subset of T cells $(67,107)$. However, the precise molecular mechanisms behind impaired STAT3 signaling in these patients remains unknown. As to the pathogenesis of the autoimmune phenomena sometimes associated with STAT1 GOF, this is not readily explained by decreased numbers of Treg cells, which appear to be normal (108). However, based on the observation that some of the features in STAT1 GOF patients overlap with the group of monogenic diseases termed interferonopathies, including an elevated IFN signature, i.e., upregulation of ISGs in the blood, this may account for some aspects of the autoimmunity present (109-111).

\section{STAT3 GOF in an Autoinflammatory Phenotype With Hypogammaglobulinemia and Lymphoproliferation}

Defective STAT3 has been described above as the genetic origin of $\mathrm{AD}$ HIES. However, more recently it has been appreciated that the opposite, namely STAT3 GOF mutations, can cause early-onset lymphoproliferation and autoimmunity (3, 112-114) (Figure 4). This severe pleiotrophic phenotype with multiorgan involvement encompasses hypogammaglobulinemia without fulfilling the criteria for common variable immunodeficiency (CVID), together with autoimmune cytopenias, lymphocytic interstitial pneumonia, enteropathy, hepatitis, and arthritis. Examination of the immunological phenotype revealed hypogammaglobulinemia, $\mathrm{T}$ cell lymphopenia (with increased fraction of double-negative $\mathrm{T}$ cells), impairment in switched memory B cells, decreased pDCs, as well as reduced regulatory $\mathrm{T}$ cells, in accordance with autoimmunity as a dominating feature $(77,112-114)$.

\section{PROPHYLAXIS AND TREATMENT OF DISEASES AFFECTING IRFs AND STATS}

A number of prophylactic and therapeutic strategies are currently available to prevent and treat PIDs in general, including those involving IRFs and STATs. Overall, since these conditions are generally severe and life threatening and often diagnosed early in life, they need correction by bone marrow transplantation (BMT) or hematopoietic stem cell transplantation (HSCT), where results are generally excellent, particularly in the case of early treatment, although depending on the underlying condition and genetic etiology. Thus, survival and cure is currently reached in up to $90 \%$ of patients undergoing HSCT for severe PIDs $(115,116)$. A prerequisite for these positive results, however, is early diagnosis and HSCT before secondary complications develop. This goal may be achieved in the future by introducing advanced programs for newborn screening for some of the major PIDs, which has proven possible in the case of SCID, even in developing countries $(117,118)$. Among the PIDs related to IRF and STAT deficiencies covered in the present review, HSCT are used for MSMD, HIES, GHIS as well as for STAT1 GOF and STAT3 GOF (119).

I addition, general vaccination strategies are relevant in the case of severe influenza in IRF7 and IRF9 deficiency. Prophylaxis with antibiotics (for example co-trimoxazole) and antifungals (such as intraconazole) are broadly employed with good results in conditions, such as HIES, CMC, GHIS, and MSMD (119). Prophylactic aciclovir treatment may be recommended in some cases of HSE caused by IRF3 deficiency, 
at least in recurrent cases. In many conditions dominated by abnormalities in B cell development and -responses with resulting hypogammaglobulinemia, immunoglobulin substitution therapy is a cornerstone of maintenance prophylaxis against infection with many years of experience and good evidence of beneficial effects in various PIDs $(115,119)$.

Novel medications include use of selective JAK inhibitors for the treatment of excessive production of type I IFN in the group of interferonopathies caused by mutations in STING or other molecules within the DNA sensing pathways $(111,120)$. Such approaches may also be relevant in a number of the described PIDs, such as STAT1 GOF and HIES, in which type I IFN is believed to play a role in generating the autoimmune state. On the other hand, HSE associated with impaired antiviral type I IFN responses might be treated with type I IFN as an adjunctive to the current standard therapy with antiviral aciclovir, although large clinical trials are ongoing but need to prove efficacy of this treatment approach.

Finally, looking into the future, new powerful technologies, such as CRISPR/Cas editing of genetic defects in PIDs is a promising avenue, which has already demonstrated potential success for medical conditions such as $\beta$-globin expression in thalassemia, and more recently in the case of certain PIDs, most notably chronic granulomatous disease (CGD) and adenosine deaminase (ADA)-severe combined immunodeficiency (SCID) (121-124). It seems highly likely that the CRISPR/Cas technique will be more widely applicable, also to some of the PIDs described here involving IRFs and STATs. Among these STAT1 and STAT3 deficiency in MSMD and AD HIES might be good candidates for gene correction.

\section{CONCLUSION AND FUTURE PERSPECTIVES}

Lessons learned from the fascinating decade-long unraveling of PIDs are numerous and have provided fundamental new insight into basic infection immunology and the correlates of protective immunity against bacterial, viral, and fungal pathogens in humans. More recently, it has also brought new knowledge about the pathogenesis of a number of conditions with underlying autoimmunity and autoinflammation. Importantly,

\section{REFERENCES}

1. Bucciol G, Moens L, Bosch B, Bossuyt X, Casanova JL, Puel A, et al. Lessons learned from the study of human inborn errors of innate immunity. J Allergy Clin Immunol. (2018). doi: 10.1016/j.jaci.2018.07.013. [Epub ahead of print].

2. Sancho-Shimizu V, Perez de Diego R, Jouanguy E, Zhang SY, Casanova JL. Inborn errors of anti-viral interferon immunity in humans. Curr Opin Virol. (2011) 1:487-96. doi: 10.1016/j.coviro.2011.10.016

3. Jhamnani RD, Rosenzweig SD. An update on gain-of-function mutations in primary immunodeficiency diseases. Curr Opin Allergy Clin Immunol. (2017) 17:391-7. doi: 10.1097/ACI.0000000000000401

4. Mogensen TH. Pathogen recognition and inflammatory signaling in innate immune defenses. Clin Microbiol Rev. (2009) 22:240-73. doi: 10.1128/CMR.00046-08

5. Paludan SR, Bowie AG. Immune sensing of DNA. Immunity (2013) 38:87080. doi: 10.1016/j.immuni.2013.05.004 these discoveries have been taken directly into clinical medicine and are thus the basis, upon which the invention and development of specific prophylactic and therapeutic strategies for patients are based.

Notably, this journey has repeatedly demonstrated significant differences between mouse and human immunity, which underscores the importance and strength of studying human patients to understand basic innate and adaptive immunology in humans. Moreover, with the increasing awareness of the major contribution of autoimmunity and autoinflammation as part of many PIDs, there is now a need for the development of approaches to treating these complex pathologies (114). Again, this reinforces the essential need for understanding basic molecular and cellular mechanisms underlying these states of dysregulated immunity.

In conclusion, improved understanding of the genetic defects and immunopathogenesis of various currently known PIDs is of fundamental importance to identify new targets and immunomodulatory agents in future management of conditions of immune dysregulation, infection, and inflammation. Given that this field of research is in a rapidly expanding phase, it is to be anticipated that many additional human inborn errors of immunity will be uncovered within the next few years. Finally, despite the extensive list of PIDs caused by mutations in IRFs and STATs as described in the present review, we are likely to learn even more in the future, thus providing new insights into both basic biology, signaling, and regulation of these transcription factors and the human pathologies their dysregulation may cause.

\section{AUTHOR CONTRIBUTIONS}

The author confirms being the sole contributor of this work and has approved it for publication.

\section{FUNDING}

TM received funding from Aarhus University Research Foundation (AUFF) (AUFF-E-215-FLS-8-66), the Danish Council for Independent Research-Medical Sciences (\# 4004-00047B), and The Lundbeck Foundation (R268-2016-3927).

6. Liu S, Cai X, Wu J, Cong Q, Chen X, Li T, et al. Phosphorylation of innate immune adaptor proteins MAVS, STING, and TRIF induces IRF3 activation. Science (2015) 347:aaa2630. doi: 10.1126/science.aaa2630

7. Ning S, Pagano JS, Barber GN. IRF7: activation, regulation, modification and function. Genes Immun. (2011) 12:399-414. doi: 10.1038/gene.2011.21

8. Bao M, Liu YJ. Regulation of TLR7/9 signaling in plasmacytoid dendritic cells. Protein Cell (2013) 4:40-52. doi: 10.1007/s13238-012-2104-8

9. Kofoed EM, Hwa V, Little B, Woods KA, Buckway CK, Tsubaki J, et al. Growth hormone insensitivity associated with a STAT5b mutation. N Engl J Med. (2003) 349:1139-47. doi: 10.1056/NEJMoa022926

10. Nadeau K, Hwa V, Rosenfeld RG. STAT5b deficiency: an unsuspected cause of growth failure, immunodeficiency, and severe pulmonary disease. J Pediatr. (2011) 158:701-8. doi: 10.1016/j.jpeds.2010.12.042

11. Stark GR, Kerr IM, Williams BR, Silverman RH, Schreiber RD. How cells respond to interferons. Annu Rev Biochem. (1998) 67:227-64. doi: 10.1146/annurev.biochem.67.1.227 
12. Kim TK, Maniatis T. The mechanism of transcriptional synergy of an in vitro assembled interferon-beta enhanceosome. Mol Cell (1997) 1:119-29. doi: 10.1016/S1097-2765(00)80013-1

13. Honda K, Taniguchi T. IRFs: master regulators of signalling by Toll-like receptors and cytosolic pattern-recognition receptors. Nat Rev Immunol. (2006) 6:644-58. doi: 10.1038/nri1900

14. Osterlund PI, Pietila TE, Veckman V, Kotenko SV, Julkunen I. IFN regulatory factor family members differentially regulate the expression of type III IFN (IFN-lambda) genes. J Immunol. (2007) 179:3434-42. doi: 10.4049/jimmunol.179.6.3434

15. Au WC, Moore PA, LaFleur DW, Tombal B, Pitha PM. Characterization of the interferon regulatory factor-7 and its potential role in the transcription activation of interferon A genes. J Biol Chem. (1998) 273:29210-7. doi: $10.1074 /$ jbc.273.44.29210

16. Marie I, Durbin JE, Levy DE. Differential viral induction of distinct interferon-alpha genes by positive feedback through interferon regulatory factor-7. EMBO J. (1998) 17:6660-9. doi: 10.1093/emboj/17.22.6660

17. Iversen MB, Paludan SR. Mechanisms of type III interferon expression. $J$ Interferon Cytokine Res. (2010) 30:573-8. doi: 10.1089/jir.2010.0063

18. Civas A, Island ML, Genin P, Morin P, Navarro S. Regulation of virus-induced interferon-A genes. Biochimie (2002) 84:643-54. doi: 10.1016/S0300-9084(02)01431-1

19. Isaacs A, Lindenmann J. Virus interference. I. The interferon. Proc R Soc Lond B Biol Sci. (1957) 147:258-67. doi: 10.1098/rspb.1957.0048

20. Taniguchi T, Fujii-Kuriyama Y, Muramatsu M. Molecular cloning of human interferon cDNA. Proc Natl Acad Sci USA. (1980) 77:4003-6. doi: 10.1073/pnas.77.7.4003

21. Maeda S, McCandliss R, Gross M, Sloma A, Familletti PC, Tabor JM, et al. Construction and identification of bacterial plasmids containing nucleotide sequence for human leukocyte interferon. Proc Natl Acad Sci USA. (1980) 77:7010-3. doi: 10.1073/pnas.77.12.7010

22. Levy DE, Garcia-Sastre A. The virus battles: IFN induction of the antiviral state and mechanisms of viral evasion. Cytokine Growth Factor Rev. (2001) 12:143-56. doi: 10.1016/S1359-6101(00)00027-7

23. Katze MG, He Y, Gale M Jr. Viruses and interferon: a fight for supremacy. Nat Rev Immunol. (2002) 2:675-87. doi: 10.1038/nri888

24. Pestka S, Krause CD, Walter MR. Interferons, interferon-like cytokines, and their receptors. Immunol Rev. (2004) 202:8-32. doi: 10.1111/j.0105-2896.2004.00204.x

25. Negishi H, Taniguchi T, Yanai H. The Interferon (IFN) class of cytokines and the IFN Regulatory Factor (IRF) Transcription factor family. Cold Spring Harb Perspect Biol. (2017) 10. doi: 10.1101/cshperspect.a028423

26. Darnell JE Jr. Studies of IFN-induced transcriptional activation uncover the Jak-Stat pathway. J Interferon Cytokine Res. (1998) 18:549-54.

27. Stark GR, Darnell JE Jr. The JAK-STAT pathway at twenty. Immunity (2012) 36:503-14. doi: 10.1016/j.immuni.2012.03.013

28. Briscoe J, Guschin D, Rogers NC, Watling D, Muller M, Horn F, et al. JAKs, STATs and signal transduction in response to the interferons and other cytokines. Philos Trans R Soc Lond B Biol Sci. (1996) 351:167-71. doi: 10.1098/rstb.1996.0013

29. Darnell JE Jr, Kerr IM, Stark GR. Jak-STAT pathways and transcriptional activation in response to IFNs and other extracellular signaling proteins. Science (1994) 264:1415-21. doi: 10.1126/science.8197455

30. Decker T, Kovarik P, Meinke A. GAS elements: a few nucleotides with a major impact on cytokine-induced gene expression. J Interferon Cytokine Res. (1997) 17:121-34. doi: 10.1089/jir.1997.17.121

31. Akira S, Nishio Y, Inoue $M$, Wang XJ, Wei S, Matsusaka T, et al. Molecular cloning of APRF, a novel IFN-stimulated gene factor 3 p91-related transcription factor involved in the gp130-mediated signaling pathway. Cell (1994) 77:63-71. doi: 10.1016/0092-8674(94)90235-6

32. Zhong Z, Wen Z, Darnell JE Jr. Stat3: a STAT family member activated by tyrosine phosphorylation in response to epidermal growth factor and interleukin-6. Science (1994) 264:95-8. doi: 10.1126/science. 8140422

33. Casrouge A, Zhang SY, Eidenschenk C, Jouanguy E, Puel A, Yang K, et al. Herpes simplex virus encephalitis in human UNC-93B deficiency. Science (2006) 314:308-12. doi: 10.1126/science.1128346
34. Zhang SY, Jouanguy E, Ugolini S, Smahi A, Elain G, Romero P, et al. TLR3 deficiency in patients with herpes simplex encephalitis. Science (2007) 317:1522-7. doi: 10.1126/science.1139522

35. Sancho-Shimizu V, Perez de Diego R, Lorenzo L, Halwani R, Alangari A, Israelsson $\mathrm{E}$, et al. Herpes simplex encephalitis in children with autosomal recessive and dominant TRIF deficiency. J Clin Invest. (2011) 121:4889-902. doi: 10.1172/JCI59259

36. Perez de Diego R, Sancho-Shimizu V, Lorenzo L, Puel A, Plancoulaine $\mathrm{S}$, Picard C, et al. Human TRAF3 adaptor molecule deficiency leads to impaired Toll-like receptor 3 response and susceptibility to herpes simplex encephalitis. Immunity (2010) 33:400-11. doi: 10.1016/j.immuni.2010.08.014

37. Herman M, Ciancanelli M, Ou YH, Lorenzo L, Klaudel-Dreszler M, Pauwels E, et al. Heterozygous TBK1 mutations impair TLR3 immunity and underlie herpes simplex encephalitis of childhood. J Exp Med. (2012) 209:1567-82. doi: $10.1084 /$ jem.20111316

38. Andersen LL, Mork N, Reinert LS, Kofod-Olsen E, Narita R, Jorgensen SE, et al. Functional IRF3 deficiency in a patient with herpes simplex encephalitis. J Exp Med. (2015) 212:1371-9. doi: 10.1084/jem.20142274

39. Mork N, Kofod-Olsen E, Sorensen KB, Bach E, Orntoft TF, Ostergaard $\mathrm{L}$, et al. Mutations in the TLR3 signaling pathway and beyond in adult patients with herpes simplex encephalitis. Genes Immun. (2015) 16:552-66. doi: 10.1038 /gene. 2015.46

40. Willmann O, Ahmad-Nejad P, Neumaier M, Hennerici MG, Fatar M. Tolllike receptor 3 immune deficiency may be causative for HSV-2-associated mollaret meningitis. Eur Neurol. (2010) 63:249-51. doi: 10.1159/000287585

41. Menachery VD, Pasieka TJ, Leib DA. Interferon regulatory factor 3dependent pathways are critical for control of herpes simplex virus type 1 central nervous system infection. J Virol. (2010) 84:9685-94. doi: 10.1128/JVI.00706-10

42. Ciancanelli MJ, Huang SX, Luthra P, Garner H, Itan Y, Volpi S, et al. Infectious disease. Life-threatening influenza and impaired interferon amplification in human IRF7 deficiency. Science (2015) 348:448-53. doi: $10.1126 /$ science.aaa 1578

43. Ciancanelli MJ, Abel L, Zhang SY, Casanova JL. Host genetics of severe influenza: from mouse Mxl to human IRF7. Curr Opin Immunol. (2016) 38:109-20. doi: 10.1016/j.coi.2015.12.002

44. Chen HW, King K, Tu J, Sanchez M, Luster AD, Shresta S. The roles of IRF3 and IRF-7 in innate antiviral immunity against dengue virus. J Immunol. (2013) 191:4194-201. doi: 10.4049/jimmunol.1300799

45. Li W, Hofer MJ, Nocon AL, Manders P, Campbell IL. Interferon regulatory factor 7 (IRF7) is required for the optimal initial control but not subsequent clearance of lymphocytic choriomeningitis virus infection in mice. Virology (2013) 439:152-62. doi: 10.1016/j.virol.2013.02.015

46. Boisson-Dupuis S, Kong XF, Okada S, Cypowyj S, Puel A, Abel L, et al. Inborn errors of human STAT1: allelic heterogeneity governs the diversity of immunological and infectious phenotypes. Curr Opin Immunol. (2012) 24:364-78. doi: 10.1016/j.coi.2012.04.011

47. Hernandez N, Melki I, Jing H, Habib T, Huang SSY, Danielson J, et al. Lifethreatening influenza pneumonitis in a child with inherited IRF9 deficiency. J Exp Med. (2018) 215:2567-85. doi: 10.1084/jem.20180628

48. Jorgensen SE, Christiansen M, Ryo LB, Gad HH, Gjedsted J, Staeheli P, et al. Defective RNA sensing by RIG-I in severe influenza virus infection. Clin Exp Immunol. (2018) 192:366-76. doi: 10.1111/cei.13120

49. Dupuis S, Dargemont C, Fieschi C, Thomassin N, Rosenzweig S, Harris $\mathrm{J}$, et al. Impairment of mycobacterial but not viral immunity by a germline human STAT1 mutation. Science (2001) 293:300-3. doi: $10.1126 /$ science. 1061154

50. Abel L, El-Baghdadi J, Bousfiha AA, Casanova JL, Schurr E. Human genetics of tuberculosis: a long and winding road. Philos Trans R Soc Lond B Biol Sci. (2014) 369:20130428. doi: 10.1098/rstb.2013.0428

51. Boisson-Dupuis S, Bustamante J, El-Baghdadi J, Camcioglu Y, Parvaneh $\mathrm{N}$, El Azbaoui $\mathrm{S}$, et al. Inherited and acquired immunodeficiencies underlying tuberculosis in childhood. Immunol Rev. (2015) 264:103-20. doi: $10.1111 /$ imr.12272

52. Bustamante J, Picard C, Boisson-Dupuis S, Abel L, Casanova JL. Genetic lessons learned from X-linked Mendelian susceptibility to 
mycobacterial diseases. Ann N Y Acad Sci. (2011) 1246:92-101. doi: 10.1111/j.1749-6632.2011.06273.x

53. Bogunovic D, Byun M, Durfee LA, Abhyankar A, Sanal O, Mansouri $\mathrm{D}$, et al. Mycobacterial disease and impaired IFN-gamma immunity in humans with inherited ISG15 deficiency. Science (2012) 337:1684-8. doi: $10.1126 /$ science. 1224026

54. Bustamante J, Arias AA, Vogt G, Picard C, Galicia LB, Prando C, et al. Germline CYBB mutations that selectively affect macrophages in kindreds with X-linked predisposition to tuberculous mycobacterial disease. Nat Immunol. (2011) 12:213-21. doi: 10.1038/ni.1992

55. Filipe-Santos O, Bustamante J, Haverkamp MH, Vinolo E, Ku CL, Puel A, et al. X-linked susceptibility to mycobacteria is caused by mutations in NEMO impairing CD40-dependent IL-12 production. J Exp Med. (2006) 203:1745-59. doi: 10.1084/jem.20060085

56. Kreins AY, Ciancanelli MJ, Okada S, Kong XF, Ramirez-Alejo N, Kilic SS, et al. Human TYK2 deficiency: mycobacterial and viral infections without hyper-IgE syndrome. J Exp Med. (2015) 212:1641-62. doi: $10.1084 /$ jem.20140280

57. Altare F, Lammas D, Revy P, Jouanguy E, Doffinger R, Lamhamedi S, et al. Inherited interleukin 12 deficiency in a child with bacille Calmette-Guerin and Salmonella enteritidis disseminated infection. J Clin Invest. (1998) 102:2035-40. doi: 10.1172/JCI4950

58. Dupuis S, Jouanguy E, Al-Hajjar S, Fieschi C, Al-Mohsen IZ, Al-Jumaah S, et al. Impaired response to interferon-alpha/beta and lethal viral disease in human STAT1 deficiency. Nat Genet. (2003) 33:388-91. doi: 10.1038/ng1097

59. Dorman SE, Picard C, Lammas D, Heyne K, van Dissel JT, Baretto R, et al. Clinical features of dominant and recessive interferon gamma receptor 1 deficiencies. Lancet (2004) 364:2113-21. doi: 10.1016/S0140-6736(04)17552-1

60. Kong XF, Martinez-Barricarte R, Kennedy J, Mele F, Lazarov T, Deenick EK, et al. Disruption of an antimycobacterial circuit between dendritic and helper T cells in human SPPL2a deficiency. Nat Immunol. (2018) 19:973-85. doi: 10.1038/s41590-018-0178-z

61. Jouanguy E, Altare F, Lamhamedi S, Revy P, Emile JF, Newport M, et al. Interferon-gamma-receptor deficiency in an infant with fatal bacille Calmette-Guerin infection. N Engl J Med. (1996) 335:1956-61. doi: 10.1056/NEJM199612263352604

62. Doffinger R, Jouanguy E, Dupuis S, Fondaneche MC, Stephan JL, Emile $J F$, et al. Partial interferon-gamma receptor signaling chain deficiency in a patient with bacille Calmette-Guerin and Mycobacterium abscessus infection. J Infect Dis. (2000) 181:379-84. doi: 10.1086/315197

63. Koscielniak E, de Boer T, Dupuis S, Naumann L, Casanova JL, Ottenhoff TH. Disseminated Mycobacterium peregrinum infection in a child with complete interferon-gamma receptor-1 deficiency. Pediatr Infect Dis J. (2003) 22:378-80. doi: 10.1097/01.inf.0000060181.71042.b5

64. Hsu AP, Sampaio EP, Khan J, Calvo KR, Lemieux JE, Patel SY, et al. Mutations in GATA2 are associated with the autosomal dominant and sporadic monocytopenia and mycobacterial infection (MonoMAC) syndrome. Blood (2011) 118:2653-5. doi: 10.1182/blood-2011-05-356352

65. Camargo JF, Lobo SA, Hsu AP, Zerbe CS, Wormser GP, Holland SM. MonoMAC syndrome in a patient with a GATA2 mutation: case report and review of the literature. Clin Infect Dis. (2013) 57:697-9. doi: 10.1093/cid/cit368

66. Sampaio EP, Bax HI, Hsu AP, Kristosturyan E, Pechacek J, Chandrasekaran $\mathrm{P}$, et al. A novel STAT1 mutation associated with disseminated mycobacterial disease. J Clin Immunol. (2012) 32:681-9. doi: 10.1007/s10875-012-9659-2

67. Casanova JL, Holland SM, Notarangelo LD. Inborn errors of human JAKs and STATs. Immunity (2012) 36:515-28. doi: 10.1016/j.immuni.2012.03.016

68. Schindler C, Darnell JE Jr. Transcriptional responses to polypeptide ligands: the JAK-STAT pathway. Annu Rev Biochem. (1995) 64:621-51.

69. Vairo D, Tassone L, Tabellini G, Tamassia N, Gasperini S, Bazzoni F, et al. Severe impairment of IFN-gamma and IFN-alpha responses in cells of a patient with a novel STAT1 splicing mutation. Blood (2011) 118:1806-17. doi: 10.1182/blood-2011-01-330571

70. Averbuch D, Chapgier A, Boisson-Dupuis S, Casanova JL, Engelhard D. The clinical spectrum of patients with deficiency of Signal Transducer and Activator of Transcription-1. Pediatr Infect Dis J. (2011) 30:352-5. doi: 10.1097/INF.0b013e3181fdff4a
71. Chapgier A, Boisson-Dupuis S, Jouanguy E, Vogt G, Feinberg J, Prochnicka-Chalufour A, et al. Novel STAT1 alleles in otherwise healthy patients with mycobacterial disease. PLoS Genet. (2006) 2:e131. doi: 10.1371/journal.pgen.0020131

72. Kristensen IA, Veirum JE, Moller BK, Christiansen M. Novel STAT1 alleles in a patient with impaired resistance to mycobacteria. J Clin Immunol. (2011) 31:265-71. doi: 10.1007/s10875-010-9480-8

73. Hambleton S, Goodbourn S, Young DF, Dickinson P, Mohamad SM, Valappil M, et al. STAT2 deficiency and susceptibility to viral illness in humans. Proc Natl Acad Sci USA. (2013) 110:3053-8. doi: 10.1073/pnas.1220098110

74. Davis SD, Schaller J, Wedgwood RJ. Job's Syndrome. Recurrent, "cold", staphylococcal abscesses. Lancet (1966) 1:1013-5. doi: 10.1016/S0140-6736(66)90119-X

75. Buckley RH, Wray BB, Belmaker EZ. Extreme hyperimmunoglobulinemia E and undue susceptibility to infection. Pediatrics (1972) 49:59-70.

76. Grimbacher B, Holland SM, Gallin JI, Greenberg F, Hill SC, Malech $\mathrm{HL}$, et al. Hyper-IgE syndrome with recurrent infections-an autosomal dominant multisystem disorder. N Engl J Med. (1999) 340:692-702. doi: 10.1056/NEJM199903043400904

77. Siegel AM, Heimall J, Freeman AF, Hsu AP, Brittain E, Brenchley JM, et al. A critical role for STAT3 transcription factor signaling in the development and maintenance of human T cell memory. Immunity (2011) 35:806-18. doi: 10.1016/j.immuni.2011.09.016

78. Sowerwine KJ, Holland SM, Freeman AF. Hyper-IgE syndrome update. Ann N Y Acad Sci. (2012) 1250:25-32. doi: 10.1111/j.1749-6632.2011.06387.x

79. Smithwick EM, Finelt M, Pahwa S, Good RA, Naspitz CK, Mendes NF, et al. Cranial synostosis in Job's syndrome. Lancet (1978) 1:826. doi: 10.1016/S0140-6736(78)93028-3

80. O'Connell AC, Puck JM, Grimbacher B, Facchetti F, Majorana A, Gallin JI, et al. Delayed eruption of permanent teeth in hyperimmunoglobulinemia E recurrent infection syndrome. Oral Surg Oral Med Oral Pathol Oral Radiol Endod. (2000) 89:177-85. doi: 10.1067/moe.2000.103129

81. Freeman AF, Avila EM, Shaw PA, Davis J, Hsu AP, Welch P, et al. Coronary artery abnormalities in Hyper-IgE syndrome. J Clin Immunol. (2011) 31:33845. doi: 10.1007/s10875-011-9515-9

82. Leonard GD, Posadas E, Herrmann PC, Anderson VL, Jaffe ES, Holland SM, et al. Non-Hodgkin's lymphoma in Job's syndrome: a case report and literature review. Leuk Lymphoma (2004) 45:2521-5. doi: $10.1080 / 10428190400004463$

83. Holland SM, DeLeo FR, Elloumi HZ, Hsu AP, Uzel G, Brodsky N, et al. STAT3 mutations in the hyper-IgE syndrome. N Engl J Med. (2007) 357:1608-19. doi: 10.1056/NEJMoa073687

84. Minegishi Y, Saito M, Tsuchiya S, Tsuge I, Takada H, Hara T, et al. Dominantnegative mutations in the DNA-binding domain of STAT3 cause hyper-IgE syndrome. Nature (2007) 448:1058-62. doi: 10.1038/nature06096

85. Renner ED, Rylaarsdam S, Anover-Sombke S, Rack AL, Reichenbach J, Carey JC, et al. Novel signal transducer and activator of transcription 3 (STAT3) mutations, reduced $\mathrm{T}(\mathrm{H}) 17$ cell numbers, and variably defective STAT3 phosphorylation in hyper-IgE syndrome. J Allergy Clin Immunol. (2008) 122:181-7. doi: 10.1016/j.jaci.2008.04.037

86. Puel A, Picard C, Lorrot M, Pons C, Chrabieh M, Lorenzo L, et al. Recurrent staphylococcal cellulitis and subcutaneous abscesses in a child with autoantibodies against IL-6. J Immunol. (2008) 180:647-54. doi: 10.4049/jimmunol.180.1.647

87. Wang WB, Levy DE, Lee CK. STAT3 negatively regulates type I IFN-mediated antiviral response. J Immunol. (2011) 187:2578-85. doi: 10.4049/jimmunol.1004128

88. Milner JD, Brenchley JM, Laurence A, Freeman AF, Hill BJ, Elias KM, et al. Impaired $\mathrm{T}(\mathrm{H}) 17$ cell differentiation in subjects with autosomal dominant hyper-IgE syndrome. Nature (2008) 452:773-6. doi: 10.1038/nature06764

89. Puel A, Cypowyj S, Bustamante J, Wright JF, Liu L, Lim HK, et al. Chronic mucocutaneous candidiasis in humans with inborn errors of interleukin-17 immunity. Science (2011) 332:65-8. doi: 10.1126/science.1200439

90. Laan M, Cui ZH, Hoshino H, Lotvall J, Sjostrand M, Gruenert DC, et al. Neutrophil recruitment by human IL-17 via C-X-C chemokine release in the airways. J Immunol. (1999) 162:2347-52.

91. Hill HR, Ochs HD, Quie PG, Clark RA, Pabst HF, Klebanoff SJ, et al. Defect in neutrophil granulocyte chemotaxis in Job's syndrome 
of recurrent "cold" staphylococcal abscesses. Lancet (1974) 2:617-9. doi: 10.1016/S0140-6736(74)91942-4

92. Ozaki K, Spolski R, Feng CG, Qi CF, Cheng J, Sher A, et al. A critical role for IL-21 in regulating immunoglobulin production. Science (2002) 298:1630-4. doi: 10.1126/science.1077002

93. Engelhardt KR, McGhee S, Winkler S, Sassi A, Woellner C, LopezHerrera G, et al. Large deletions and point mutations involving the dedicator of cytokinesis 8 (DOCK8) in the autosomal-recessive form of hyper-IgE syndrome. J Allergy Clin Immunol. (2009) 124:1289-302.e4. doi: 10.1016/j.jaci.2009.10.038

94. Woellner C, Schaffer AA, Puck JM, Renner ED, Knebel C, Holland SM, et al. The hyper IgE syndrome and mutations in TYK2. Immunity (2007) 26:535. doi: 10.1016/j.immuni.2007.05.007

95. Yang L, Fliegauf $M$, Grimbacher B. Hyper-IgE syndromes: reviewing PGM3 deficiency. Curr Opin Pediatr. (2014) 26:697-703. doi: 10.1097/MOP.0000000000000158

96. Pugliese-Pires PN, Tonelli CA, Dora JM, Silva PC, Czepielewski M, Simoni G, et al. A novel STAT5B mutation causing GH insensitivity syndrome associated with hyperprolactinemia and immune dysfunction in two male siblings. Eur J Endocrinol. (2010) 163:349-55. doi: 10.1530/EJE-10-0272

97. Snow JW, Abraham N, Ma MC, Herndier BG, Pastuszak AW, Goldsmith MA. Loss of tolerance and autoimmunity affecting multiple organs in STAT5A/5B-deficient mice. J Immunol. (2003) 171:5042-50. doi: $10.4049 /$ jimmunol.171.10.5042

98. van de Veerdonk FL, Plantinga TS, Hoischen A, Smeekens SP, Joosten LA, Gilissen C, et al. STAT1 mutations in autosomal dominant chronic mucocutaneous candidiasis. N Engl J Med. (2011) 365:54-61. doi: 10.1056/NEJMoa1100102

99. Liu L, Okada S, Kong XF, Kreins AY, Cypowyj S, Abhyankar A, et al. Gain-of-function human STAT1 mutations impair IL-17 immunity and underlie chronic mucocutaneous candidiasis. J Exp Med. (2011) 208:163548. doi: 10.1084/jem.20110958

100. Takezaki S, Yamada M, Kato M, Park MJ, Maruyama K, Yamazaki Y, et al. Chronic mucocutaneous candidiasis caused by a gain-of-function mutation in the STAT1 DNA-binding domain. J Immunol. (2012) 189:15216. doi: 10.4049/jimmunol.1200926

101. Yamazaki Y, Yamada M, Kawai T, Morio T, Onodera M, Ueki M, et al. Two novel gain-of-function mutations of STAT1 responsible for chronic mucocutaneous candidiasis disease: impaired production of IL-17A and IL-22, and the presence of anti-IL-17F autoantibody. J Immunol. (2014) 193:4880-7. doi: 10.4049/jimmunol.1401467

102. Smeekens SP, Plantinga TS, van de Veerdonk FL, Heinhuis B, Hoischen A, Joosten LA, et al. STAT1 hyperphosphorylation and defective IL12R/IL23R signaling underlie defective immunity in autosomal dominant chronic mucocutaneous candidiasis. PLoS ONE (2011) 6:e29248. doi: 10.1371/journal.pone.0029248

103. Nielsen J, Kofod-Olsen E, Spaun E, Larsen CS, Christiansen M, Mogensen TH. A STAT1-gain-of-function mutation causing Th17 deficiency with chronic mucocutaneous candidiasis, psoriasiform hyperkeratosis and dermatophytosis. BMJ Case Rep. (2015) 2015. doi: 10.1136/bcr-2015-211372

104. Kagawa R, Fujiki R, Tsumura M, Sakata S, Nishimura S, Itan Y, et al. Alanine-scanning mutagenesis of human signal transducer and activator of transcription 1 to estimate loss- or gain-of-function variants. J Allergy Clin Immunol. (2017) 140:232-41. doi: 10.1016/j.jaci.2016.09.035

105. Toubiana J, Okada S, Hiller J, Oleastro M, Lagos Gomez M, Aldave Becerra JC, et al. Heterozygous STAT1 gain-of-function mutations underlie an unexpectedly broad clinical phenotype. Blood (2016) 127:3154-64. doi: 10.1182/blood-2015-11-679902

106. Zhou L, Ivanov II, Spolski R, Min R, Shenderov K, Egawa T, et al. IL-6 programs $\mathrm{T}(\mathrm{H})-17$ cell differentiation by promoting sequential engagement of the IL-21 and IL-23 pathways. Nat Immunol. (2007) 8:967-74. doi: $10.1038 /$ ni1488

107. Chen M, Chen G, Nie H, Zhang X, Niu X, Zang YC, et al. Regulatory effects of IFN-beta on production of osteopontin and IL-17 by CD4+ T Cells in MS. Eur J Immunol. (2009) 39:2525-36. doi: 10.1002/eji.2008 38879

108. Uzel G, Sampaio EP, Lawrence MG, Hsu AP, Hackett M, Dorsey MJ, et al. Dominant gain-of-function STAT1 mutations in FOXP3 wild-type immune dysregulation-polyendocrinopathy-enteropathy-X-linked-like syndrome.
J Allergy Clin Immunol. (2013) 131:1611-23. doi: 10.1016/j.jaci.2012. 11.054

109. Crow YJ. Type I interferonopathies: a novel set of inborn errors of immunity. Ann N Y Acad Sci. (2011) 1238:91-8. doi: 10.1111/j.1749-6632.2011.06220.x

110. Liu BC, Sarhan J, Poltorak A. Host-intrinsic interferon status in infection and immunity. Trends Mol Med. (2018) 24:658-68. doi: 10.1016/j.molmed.2018.06.004

111. Rodero MP, Crow YJ. Type I interferon-mediated monogenic autoinflammation: the type I interferonopathies, a conceptual overview. $J$ Exp Med. (2016) 213:2527-38. doi: 10.1084/jem.20161596

112. Flanagan SE, Haapaniemi E, Russell MA, Caswell R, Allen HL, De Franco E, et al. Activating germline mutations in STAT3 cause early-onset multi-organ autoimmune disease. Nat Genet. (2014) 46:812-4. doi: 10.1038/ng.3040

113. Milner JD, Vogel TP, Forbes L, Ma CA, Stray-Pedersen A, Niemela JE, et al. Early-onset lymphoproliferation and autoimmunity caused by germline STAT3 gain-of-function mutations. Blood (2015) 125:591-9. doi: 10.1182/blood-2014-09-602763

114. Haapaniemi EM, Kaustio M, Rajala HL, van Adrichem AJ, Kainulainen L, Glumoff V, et al. Autoimmunity, hypogammaglobulinemia, lymphoproliferation, and mycobacterial disease in patients with activating mutations in STAT3. Blood (2015) 125:639-48. doi: 10.1182/blood-2014-04-570101

115. Mahlaoui N, Warnatz K, Jones A, Workman S, Cant A. Advances in the care of Primary Immunodeficiencies (PIDs): from birth to adulthood. J Clin Immunol. (2017) 37:452-60. doi: 10.1007/s10875-017-0401-y

116. Marsh R, Hebert KM, Keesler D, Boelens JJ, Dvorak C, Eckrich MJ, et al. Practice pattern changes and improvements in hematopoietic cell transplantation for primary immunodeficiencies. J Allergy Clin Immunol. (2018) 142:2004-7. doi: 10.1016/j.jaci.2018.08.010

117. King JR, Hammarstrom L. Newborn screening for primary immunodeficiency diseases: history, current and future practice. $J$ Clin Immunol. (2018) 38:56-66. doi: 10.1007/s10875-017-0455-x

118. Al-Mousa H, Al-Dakheel G, Jabr A, Elbadaoui F, Abouelhoda M, Baig M, et al. High incidence of severe combined immunodeficiency disease in Saudi Arabia detected through combined $\mathrm{T}$ cell receptor excision circle and next generation sequencing of newborn dried blood spots. Front Immunol. (2018) 9:782. doi: 10.3389/fimmu.2018.00782

119. Bonilla FA, Khan DA, Ballas ZK, Chinen J, Frank MM, Hsu JT, et al. Practice parameter for the diagnosis and management of primary immunodeficiency. J Allergy Clin Immunol. (2015) 136:1186-205.e1-78. doi: 10.1016/j.jaci.2015.04.049

120. Rodero MP, Fremond ML, Rice GI, Neven B, Crow YJ. JAK inhibition in STING-associated interferonopathy. Ann Rheum Dis. (2016) 75:e75. doi: 10.1136/annrheumdis-2016-210504

121. Dever DP, Bak RO, Reinisch A, Camarena J, Washington G, Nicolas CE, et al. CRISPR/Cas9 beta-globin gene targeting in human haematopoietic stem cells. Nature (2016) 539:384-9. doi: 10.1038/nature20134

122. De Ravin SS, Li L, Wu X, Choi U, Allen C, Koontz S, et al. CRISPRCas9 gene repair of hematopoietic stem cells from patients with Xlinked chronic granulomatous disease. Sci Transl Med. (2017) 9:eaah3480. doi: 10.1126/scitranslmed.aah3480

123. Schiroli G, Ferrari S, Conway A, Jacob A, Capo V, Albano L, et al. Preclinical modeling highlights the therapeutic potential of hematopoietic stem cell gene editing for correction of SCID-X1. Sci Transl Med. (2017) 9:eaan0820. doi: $10.1126 /$ scitranslmed.aan0820

124. Chinen J, Cowan MJ. Advances series, advances and highlights in primary immunodeficiencies 2017. J Allergy Clin Immunol. (2018) 142:1041-51. doi: 10.1016/j.jaci.2018.08.016

Conflict of Interest Statement: The author declares that the research was conducted in the absence of any commercial or financial relationships that could be construed as a potential conflict of interest.

Copyright $(2019$ Mogensen. This is an open-access article distributed under the terms of the Creative Commons Attribution License (CC BY). The use, distribution or reproduction in other forums is permitted, provided the original author(s) and the copyright owner(s) are credited and that the original publication in this journal is cited, in accordance with accepted academic practice. No use, distribution or reproduction is permitted which does not comply with these terms. 